\title{
Direito Econômico Ambiental e o instituto do Seguro ambiental: estudos comparativos entre Brasil e Argentina
}

\author{
Environmental Economic Law and Environmental Insurance: \\ comparative studies between Brazil and Argentina
}

\section{Leonardo Alves Corrêa}

Professor de Direito Econômico da Universidade Federal de Juiz de Fora. Doutorando em Direito Público pela PUC-Minas.

E-mail: leoalvescorrea@gmail.com

\section{Thiago Magalhães Machado}

Bacharel em Direito pela Universidade Federal de Juiz de Fora. Advogado. E-mail: magalhaeskta@hotmail.com

RECEBIDO EM: 04.09.12

AProvado EM: 20.11.12

\section{RESUMo}

A efetivação da proteção ambiental depende de um conjunto de instrumentos jurídicos e institucionais aptos a garantir a tutela preventiva e repressiva do meio ambiente ecologicamente equilibrado. O Direito Econômico Ambiental tem como objetivo estudar os mecanismos de política econômica, segundo o qual o Estado intervém na economia com a finalidade de adequar a conduta do agente econômico aos princípios de proteção ambiental. O seguro ambiental - seja ele obrigatório ou facultativo - constitui um importante instrumento de garantia de um ambiente harmonioso. O presente artigo visa estudar o instituto do seguro ambiental a partir do estudo comparativo legislativo entre Brasil e Argentina.

Palavras-chave: Direito Econômico Ambiental. Meio ambiente. Seguro AMBIENTAL. 


\begin{abstract}
The effectiveness of environmental protection depends on a set of legal and institutional instruments capable of guaranteeing the protection of preventive and repressive ecologically balanced environment. The Environmental Economic Law aims to study the mechanisms of economic policy, according to which the state intervenes in the economy in order to adapt the behavior of economic agents to the principles of environmental protection. Environmental insurance - whether mandatory or voluntary - is an important means of ensuring a harmonious environment. This paper aims to study the institute of environmental insurance from legislative comparative study between Brazil and Argentina.
\end{abstract}

Keywords: Environmental Economic Law. Environment. Environmental INSURANCE.

Sumário: Introdução. 1. Direito Econômico Ambiental e seguro ambiental: aspectos introdutórios. 1.1 Seguro ambiental como instrumento do Direito Privado. 1.2 Seguro ambiental como instrumento de intervenção do Estado na economia. 2. O seguro ambiental no ordenamento jurídico argentino. $2.1 \mathrm{O}$ princípio da prevenção no direito argentino. 2.2 Legislação pertinente sobre o seguro ambiental argentino. 2.3 As resoluções normativas tendentes a efetivar a obrigatoriedade do seguro ambiental argentino. 2.3.1 Atividades que necessitam da contratação de seguro ambiental. 2.3.2 Os sujeitos do contrato de seguro e a definição do dano a ser reparado. 2.4 A esfera de cobertura do seguro ambiental. 2.5 O valor da apólice. 2.6 O atual estágio do seguro ambiental na Argentina. 3. Considerações sobre os projetos de lei em trâmite no Congresso Nacional que buscam implementar o seguro ambiental no Brasil. 3.1 O projeto de lei $\mathrm{n}^{\circ}$ 937/2003. 3.1.1 Posicionamentos favoráveis ao projeto. 3.1.2 Posicionamentos contrários ao projeto. $3.2 \mathrm{O}$ projeto de lei $\mathrm{n}^{\mathrm{o}} 2313 / 2003$. 3.2.1 Posicionamentos favoráveis ao projeto. 3.2.2 Posicionamentos contrários ao projeto. 3.3 A proposta de emenda à Constituição $n^{\circ}$ 82/2007. 3.3.1 Repercussões do projeto. Conclusão. Referências. 


\section{INTRODUÇÃo}

O presente trabalho ${ }^{328}$ tem o objetivo de analisar o seguro ambiental a partir da ótica do Direito Econômico Ambiental. Nesse sentido, o seguro ambiental é concebido como um instrumento de política econômica, público e privado, apto a garantir os mecanismos econômicos de recuperação/reparação do dano ambiental. $\mathrm{O}$ artigo pretende questionar: qual o atual estágio de discussão institucional sobre seguro ambiental no Brasil? As atuais medidas legislativas em apreciação no Congresso Nacional representam um efetivo avanço na concretização de um marco regulatório constitucionalmente adequado?

Do ponto de vista metodológico, o presente trabalho utilizará o método jurídico-propositivo, ou seja, aquele destinado à realização de questionamentos, tendo como base, a apreciação de projetos de lei em andamento em nossas Casas Legislativas. Para tanto, serão analisados os projetos de lei em trâmite no Congresso Nacional que objetivam, justamente, implementar o instituto em nosso ordenamento jurídico. A metodologia em questão foi selecionada em virtude de o tema abordado se tratar de inovação legislativa. Ademais, o artigo abordará a questão a partir do viés legislativo-comparativo, na medida em que analisará o atual estágio legislativo do seguro ambiental no ordenamento jurídico argentino.

A princípio, traçaremos as diretrizes básicas que permeiam o tema, trazendo, primordialmente, elementos de direito ambiental, direito securitário e direito econômico, que se entrelaçam no seguro ambiental. Com relação ao direito ambiental, traremos à discussão alguns princípios relacionados à matéria, quais sejam: o princípio da prevenção e o princípio do poluidor-pagador. No ramo securitário, explicaremos os elementos básicos do contrato de seguro, com o intuito de situar o leitor no que diz respeito às regras e práticas comuns a este tipo de contrato. A inclusão do Direito Econômico ocorre em razão de alguns projetos de lei cogitarem a instituição do seguro ambiental de maneira compulsória, o que certamente produziria efeitos tanto no mercado empresarial, como nas futuras práticas econômicas estatais.

Após uma breve explanação dos elementos que permeiam o seguro ambiental, passaremos ao estudo da aplicação do instituto na Argentina. A partir das técnicas do direito comparado, visualizaremos os pontos positivos e negativos do seguro ambiental naquele país, o que permitirá uma análise mais apurada dos projetos existentes no Brasil.

Por fim, abordaremos os projetos de lei nacionais que objetivam a criação do seguro ambiental, estando estes no aguardo da apreciação de nossos parlamentares. Serão expostas as opiniões e motivações das diversas comissões

\footnotetext{
${ }^{328}$ Os autores agradecem o apoio financeiro e institucional da FAPEMIG, PUC-MG e UFJF.
} 
legislativas pelas quais os projetos passaram até o momento. Desde já, revelamos que algumas dessas comissões opinaram pela aprovação, enquanto outras se manifestaram em sentido contrário. Desta feita, partiremos da análise dos projetos de lei em trâmite no Congresso Nacional.

\section{Direito Econômico Ambiental e seguro ambiental: aspectos INTRODUTÓRIOS}

\subsection{Seguro ambiental como instrumento do Direito Privado}

O contrato de seguro, disciplinado no Código Civil a partir de seu artigo $757^{329}$, configura-se com a relação jurídica entre segurado e segurador; este garante determinado interesse ou bem daquele, previamente estabelecido na apólice de seguro, mediante o pagamento de quantia pactuada entre as partes, chamada de prêmio. O prêmio é de suma importância para o contrato de seguro, uma vez que viabiliza a circulação de capital no seio da seguradora, permitindo que esta adquira estabilidade para honrar seus compromissos (TZIRULNIK apud TRENNEPOHL, 2008). Trata-se do princípio do mutualismo, de suma importância para o direito securitário, segundo o qual os indivíduos segurados, através do pagamento dos prêmios, contribuem para cobrir os gastos da seguradora com a reparação do dano de determinado segurado. Visualiza-se, portanto, solidariamente, uma repartição dos custos entre os segurados, para que se possa garantir a indenização quando da ocorrência do sinistro.

Devemos trazer à tona, ainda, o princípio da boa-fé, inerente não só ao contrato de seguro, mas também a toda e qualquer relação contratual, constituindo-se como princípio geral e norteador do Código Civil ${ }^{330}$. Este princípio se revela especialmente pertinente ao contrato de seguro no momento de sua celebração, especificamente quando o segurado presta as informações do bem objeto do seguro. Isto porque, conforme preceituam os artigos $765 \mathrm{e}$ 766 do Código Civil, ${ }^{331}$ caso fique provado que as declarações prestadas não

\footnotetext{
${ }^{329}$ Art. 757, Código Civil: "Pelo contrato de seguro, o segurador se obriga, mediante o pagamento do prêmio, a garantir interesse legítimo do segurado, relativo a pessoa ou a coisa, contra riscos predeterminados".

${ }^{330}$ Art. 422, Código Civil: "Os contratantes são obrigados a guardar, assim na conclusão do contrato, como em sua execução, os princípios de probidade e boa-fé".

${ }^{331}$ Art. 765, Código Civil: "O segurado e o segurador são obrigados a guardar na conclusão e na execução do contrato, a mais estrita boa-fé e veracidade, tanto a respeito do objeto como das circunstâncias e declarações a ele concernentes".

Art. 766, Código Civil: "Se o segurado, por si ou por seu representante, fizer declarações inexatas ou omitir circunstâncias que possam influir na aceitação da proposta ou na taxa do prêmio, perderá o direito à garantia, além de ficar obrigado ao prêmio vencido".
} 
correspondem à realidade, ou que são inexatas, o segurado poderá vir a perder o direito à cobertura oferecida pela seguradora.

No tocante à natureza jurídica do contrato de seguro, apesar de divergências, prevalece o entendimento de alguns autores, tais quais Caio Mário e Maria Helena Diniz, que apontam ser este um contrato bilateral, de adesão, oneroso, consensual e aleatório. É bilateral porque necessita da manifestação de vontade de ambas as partes. A adesão se verifica a partir do momento que, na maioria dos casos, o segurado tem que aceitar os termos propostos pela seguradora quando da contratação de uma apólice previamente estipulada, sobre a qual não tem participação em sua elaboração. A onerosidade se deve ao fato de que tanto o segurado quanto a seguradora possuem ônus e vantagens financeiras. O primeiro paga o prêmio regularmente, enquanto que o segundo garante o ressarcimento do dano quando da ocorrência do sinistro, independente do momento em que ocorrer, desde que posterior à celebração do contrato.

No que se refere a ser consensual, há divergência doutrinária. Alguns autores, como Maria Helena Diniz e Roberto Durço, entendem que o contrato de seguro deve ser formal, devendo a forma escrita ser obrigatória. Outros, como Caio Mário, ao revés, consideram suficiente a simples manifestação de vontade das partes, sendo o documento apenas um elemento probatório do contrato. Por fim, temos a aleatoriedade, que diz respeito ao risco inerente a qualquer contrato de seguro, visto que, quando da celebração do contrato, não há certeza se o sinistro ocorrerá ou não.

Em virtude de o seguro ambiental ser uma ferramenta nova a ser implementada em nosso ordenamento jurídico, certamente surgirão dificuldades neste momento inicial. Dito isso, é de grande importância citarmos operações próprias do contrato de seguro que facilitariam tal implementação, sobretudo no que diz respeito à facilitação na distribuição dos riscos por parte das seguradoras. A primeira é o resseguro, prática comum no mercado securitário, que consiste na divisão dos riscos assumidos por determinada seguradora com uma resseguradora, quando aquela percebe que não possui capacidade financeira para arcar com os custos da indenização, visando, assim, garantir a liquidação no caso de ocorrência do sinistro. Walter Polido (2007, p. 22) ensina, ainda, que a união entre seguradoras ou resseguradoras, na formação de pools, seria interessante para a implementação do seguro ambiental em nosso país, na medida em que superariam as dificuldades impostas a este tipo de seguro, sobretudo as de caráter técnico e o risco financeiro que cada seguradora assumiria se agisse isoladamente.

No mesmo sentido, outra prática da qual o seguro ambiental poderia se valer é o co-seguro, operação entre seguradoras na qual há a repartição dos riscos de um único contrato. Cada seguradora responde perante o segurado na medida de suas responsabilidades, conforme estipulado na formação do contrato. 


\subsection{Seguro ambiental como instrumento de intervenção do Estado NA ECONOMIA}

Ao implementar o seguro ambiental em nosso ordenamento jurídico, o Estado está inegavelmente intervindo na economia. Ao que nos parece, tal prática é salutar, em função de inexistirem condições iniciais capazes de fomentar, tão somente pela iniciativa privada, o instituto que se deseja criar. Desta feita, está o Estado agindo em prol da sociedade, o que é um de seus objetivos. Corroborando esta idéia, citamos a lição de Moreira (2005, p. 4):

Através dos mecanismos jurídicos intervencionistas, o Estado se insere no domínio econômico privado buscando produzir resultados macro ou microeconômicos diversos daqueles que adviriam caso intervenção não houvesse. A intervenção é sempre inovadora, no sentido de que deve procurar a alteração dos parâmetros comportamentais originários ao mercado no qual se intervém (caso contrário, seria supérflua ou incidiria em desvio de função).

Neste sentido, vemos que a intervenção do Estado na economia muitas vezes se faz necessária, como ocorre no presente caso. É o que nos ensina Washington Peluso Albino de Souza (2003, p. 356, 357):

Na medida em que os empreendimentos não interessavam à iniciativa privada, ou quando esta praticava atos que prejudicassem os interesses da coletividade, foi criada a Empresa Pública para ocupação daquelas áreas. $[\ldots]$

Os argumentos oferecidos em contraposição à prática da ação econômica do Estado, no mercado, por esta Empresa, são os mesmos das demais empresas estatais, pois afirmam que, uma vez cumprida a sua "função supletiva" da iniciativa privada, e "amadurecidas", tendo atingido a possibilidade de competir normalmente com as particulares e, como estas, de gerar lucros, devam ser privatizadas.

Ao tratarmos o seguro ambiental sob a ótica do Direito Econômico, isto é, como uma política econômica de tutela do meio ambiente, o principal debate a ser enfrentando consiste em determinar a legitimidade de obrigatoriedade ou não do seguro ambiental.

Em defesa da implementação do seguro ambiental no ordenamento jurídico, mas sem que tal ferramenta possua caráter obrigatório, temos aqueles 
que dizem ser tal medida incompatível com a natureza do risco e com o estágio de desenvolvimento deste ramo securitário em nosso país (POLIDO, 2007).

Argumentam que o seguro ambiental não pode ser visto como um tributo, o que aconteceria se fosse implementado como obrigatório, além de haver o risco de ser visto, por alguns, como uma licença para poluir. Dizem, ainda, que o Estado não pode repassar o controle e gestão das fontes poluidoras à iniciativa privada, visto que tais ônus seriam seus. Para tanto, sustentam que não há legislação capaz de obrigar qualquer seguradora a oferecer determinado tipo de seguro ao mercado, sobretudo por força do princípio constitucional da livre iniciativa, pelo que ocorrendo tal afronta evidente seria o caráter inconstitucional da obrigatoriedade imposta às seguradoras.

No sentido de refutar a obrigatoriedade do seguro ambiental, Polido (2007, p. 20) cita alguns motivos que justificariam sua posição:

(i) a obrigatoriedade impede o desenvolvimento de experiências próprias de cada Seguradora.

(ii) o seguro obrigatório é instrumento ineficaz, na medida em que não consegue a adesão integral dos Seguradores para a aceitação dos riscos inerentes. Deve ser preservado - sempre - o direito do Segurador de avaliar, mensurar e tarifar cada risco, de acordo com seus métodos próprios.

(iii) não é função do mercado segurador privado controlar o cumprimento de normas ambientais - relativas à segurança e prevenção de acidentes. A tarefa é de competência original da Administração Pública. O seguro não pode ser transformado, de forma alguma, em licença para poluir.

(iv) a compulsoriedade do seguro pode apresentar impacto negativo para pequenos e médios negócios, inviabilizando-os - caso a apólice de seguro venha a ser considerada como instrumento para a autorização de funcionamento das empresas.

(v) em última instância, o seguro deve ser apenas mais uma dentre outras garantias financeiras - de livre opção para o cidadão-empreendedor, que o ordenamento jurídico pode exigir.

Aqueles que advogam em favor da obrigatoriedade sustentam que os sujeitos tutelados pelo seguro ambiental, isto é, a sociedade analisada com um todo, de maneira difusa, e especificamente o meio ambiente, que é bem 
coletivo e a todos pertence, não podem esperar que os empresários que atuam no mercado securitário tomem, conscientemente, a iniciativa de se adequar a esta nova ferramenta de proteção ambiental. Ademais, enquanto não houver demanda, o que fatalmente ocorreria com a obrigatoriedade do seguro ambiental, as seguradoras não oferecerão este tipo de produto no mercado.

Rebatendo aqueles que não aceitam a obrigatoriedade, argumentam que essa imposição não seria de forma alguma uma licença para poluir. Isto porque, ao assumirem os riscos do contrato de seguro, as seguradoras passariam a fiscalizar as atividades dsa empresas poluidoras, na medida em que quanto mais estas poluírem, maior seria o preço do prêmio a ser pago por elas (BOJUNGA, 2009).

Ventila-se, em um dos projetos de lei que objetiva implementar o seguro ambiental obrigatório, a criação de uma empresa seguradora estatal, que ofereceria o produto às empresas eminentemente poluidoras, ao menos em um primeiro momento, até que as seguradoras privadas possuam condições de fazerem o mesmo e possam concorrer diretamente com a empresa estatal, suplantando-a, se for o caso, posteriormente.

De acordo com informações de Luiz Bojunga (2009), referida empresa estatal, que se chamaria "Seguradora Ambiental do Brasil", seria subordinada ao Ministério da Fazenda e fiscalizada pela Superintendência de Seguros Privados (SUSEP) e pelo Conselho Nacional de Seguros Privados (CNSP), além de ter participação da iniciativa privada.

\section{O SEgURO AMBIENTAL NO ORDENAMENTO JURÍDICO ARGENTINO}

\subsection{O PRINCÍPIO DA PREVENÇÃO NO DIREITO ARGENTINO}

No âmbito do Direito Argentino, o princípio da prevenção é consagrado no artigo 41 da Constituição Nacional da Argentina e do artigo $\mathbf{4}^{\mathbf{0} 332}$, da Lei Geral do Meio Ambiente, que trata especificamente do princípio da prevenção. Neste sentido, ensina Martín Andrés Frúgoli (2009):

Además, se ha dicho que este principio tiene raigambre constitucional en la cláusula ambiental del art. 41 de la Constitución Nacional, - y ha sido establecido en numerosos instrumentos jurídicos internacionales. Esta cláusula constitucional es una norma plenamente operativa. Ante la

\footnotetext{
${ }^{332}$ Art. 4\%: "La interpretación y aplicación de la presente ley, y de toda otra norma a través de la cual se ejecute la política Ambiental, estarán sujetas al cumplimiento de los siguientes principios: [...] Principio de prevención: Las causas y las fuentes de los problemas ambientales se atenderán en forma prioritaria e integrada, tratando de prevenir los efectos negativos que sobre el ambiente se pueden producir."
} 
carencia de norma reglamentaria, el juez deberá aplicar directamente la Constitución, efectuando la labor de integración necesaria. Con lo que su aplicación es insoslayable.

De acordo com Néstor Cafferatta (2008), professor de direito ambiental da Universidade Nacional de Buenos Aires, o princípio da prevenção vem sendo aplicado de maneira incisiva pela jurisprudência argentina, sendo considerado o mais importante do direito ambiental daquele país. Guadalupe Torres (2008) traduz muito bem a relevância deste princípio para as normas de direito ambiental, revelando a importância do seguro ambiental como forma de aplicá-lo, dizendo que:

La falta de prevención en materia ambiental constituye actualmente el principal problema a atacar por nuestro país y de él se desprenden otros tantos problemas ambientales.

En la práctica comparada la prevención está considerada la regla de oro en materia ambiental dado que cuando un daño al ambiente se produce, resulta muy difícil cuando no imposible, volver las cosas a su estado anterior. Ya sea por que estas resultan irrecomponibles en especie o bien, por que el costo de esa recomposición no puede ser económicamente asumido por sus responsables. El derecho ambiental debe centrar su atención en el énfasis preventivo ya que la vía sancionadora o coactiva se encuentre muy limitada en cuanto a su eficacia a posteriori.

Asi el seguro ambiental viene a cumplir un papel fundamental como instrumento de control ambiental.

Como visto, o princípio da prevenção se revela de suma importância para o seguro ambiental, na medida em que se analisa, aqui, a relação entre o fato e o dano ambiental causado. Sendo certa essa relação, bem como o resultado que produzirá, a principal medida a ser adotada é prevenir a ocorrência deste, já que se tratando de meio ambiente é sempre melhor evitar que o dano aconteça do que buscar repará-lo depois do sinistro. Isso porque na maioria das vezes tal reparação se revela muito difícil ou até mesmo impossível, em virtude das peculiaridades de cada ecossistema. É nesta última hipótese que se revela a relevância do princípio da prevenção, já que sendo impossível retornar o meio ambiente ao seu estado anterior, o dano causado será irremediável. 


\subsection{LegislaÇÃo PERTINENTE SOBRE O SEGURO AMBIENTAL ARGENTINO}

O sistema legal da maior parte das sociedades enfrenta, na prática, problemas semelhantes, que, embora solucionados de maneiras distintas, apresentam resultados similares. $\mathrm{O}$ objeto de comparação deve ser retirado do ordenamento jurídico comparado e incluído em nosso sistema, de maneira adaptada, para satisfazer as necessidades de nosso ordenamento. $\mathrm{O}$ Direito Comparado possui essa importância, permitindo que se vislumbrem convergências e divergências entre os sistemas jurídicos, de modo a enriquecer nossas fontes de direito. A relevância do estudo do seguro ambiental argentino se dá na observação do seu implemento e da forma como o instituto é exigido naquele país, de modo que possamos tirar valiosas lições do que pode ou não ser proveitoso quando chegar o momento de sua implementação no Brasil.

Antes de mais nada, devemos trazer à discussão a Constituição Argentina, de 1994, que, em seu artigo $41^{333}$, pedra fundamental das demais normas ambientais daquele ordenamento, assegura a todas as pessoas um meio ambiente saudável e equilibrado, estabelecendo que a reparação do dano ambiental deve ser prioritária para aquele que o causa, de acordo com o que a lei estabelecer. Com isso, observamos que a referida norma constitucional transfere ao legislador ordinário a função de criar regras e pressupostos mínimos de proteção ao meio ambiente, cabendo a cada Província complementar tais normas, caso se faça necessário.

Foi seguindo os ditames constitucionais que o legislador ordinário editou a Lei Geral do Meio Ambiente - Lei de número 25.675, de 2002, que incorporou o seguro ambiental obrigatório ao ordenamento jurídico, como um instrumento de proteção ao meio ambiente. Esta lei prevê, em seu artigo $22^{334}$, em quais casos a contratação de seguro ambiental é obrigatória, assim como quem deve contratá-lo. Temos que referida contratação será obrigatória para todos aqueles que realizem atividades perigosas ao meio ambiente, seja pessoa física ou jurídica, neste último caso, grande ou pequena empresa, bastando apenas que exerça tais atividades.

\footnotetext{
${ }^{333}$ Art. 41: "Todos los habitantes gozan del derecho a un ambiente sano, equilibrado, apto para el desarrollo humano y para que las actividades productivas satisfagan las necesidades presentes sin comprometer las de las generaciones futuras; $y$ tienen el deber de preservarlo. El daño ambiental generará prioritariamente la obligación de recomponer, según lo establezca la ley. [...] Corresponde a la Nación dictar las normas que contengan los presupuestos mínimos de protección, y a las provincias, las necesarias para complementarlas, sin que aquellas alteren las jurisdicciones locales."

334 "Art. 22: Toda persona física o jurídica, pública o privada, que realice actividades riesgosas para el ambiente, los ecosistemas y sus elementos constitutivos, deberá contratar un seguro de cobertura con entidad suficiente para garantizar el financiamiento de la recomposición del daño que en su tipo pudiere producir; asimismo, según el caso y las posibilidades, podrá integrar un fondo de restauración ambiental que posibilite la instrumentación de acciones de reparación."
} 
Em seguida, no artigo $27^{335}$, a lei em comento, em consonância com o instituto ora estudado, trata da prevenção e reparação do dano ambiental em seu aspecto coletivo. Sendo assim, temos que o seguro ambiental obrigatório, naquele país, através da interpretação da Lei n. 25.675, cobre apenas o dano ambiental coletivo, de caráter difuso, próprio aos princípios do direito ambiental. Havendo algum indivíduo isoladamente lesado pelo dano ambiental, este deverá buscar as vias judiciais comuns para ver ressarcido seu prejuízo. Ou seja, deverá valer-se dos institutos da responsabilidade civil, previstos no Código Civil Argentino, não podendo acionar a seguradora que, como já dito, garante apenas o dano ambiental coletivo.

$\mathrm{O}$ artigo $28^{336}$, por sua vez, prevê que a responsabilidade do poluidor é objetiva, e deverá restabelecer o meio ambiente ao estado anterior ao dano causado. Não sendo possível tal restauração, a quantia a ser paga pela seguradora terá caráter substitutivo, indenizatório, a ser depositada em um Fundo de Compensação Ambiental, que utilizará os recursos ali presentes em prol do meio ambiente.

Insta observar que, poucos meses antes da promulgação da lei que instituiu o seguro obrigatório na Argentina, foram promulgadas duas leis - de números 25.612 e 25.670 - que ofereceram outras ferramentas jurídicas ao potencial poluidor, que poderia utilizá-las para reparar o dano causado. São elas: contratação de um seguro de responsabilidade civil, oferecimento de caução ou fiança bancária, constituição de um auto-seguro ou o implemento de um fundo de reparação. Atendo-se ao recorte metodológico do presente trabalho, que se limita à análise do seguro ambiental, os demais institutos não serão aqui estudados, valendo a menção para fins de notícia da existência, no ordenamento argentino, de mecanismos alternativos.

Vê-se, pois, que o agente poluidor argentino possui diversos mecanismos para atender à legislação ambiental no que se refere à reparação do dano causado. Não obstante, certa parcela da doutrina argentina ${ }^{337}$ critica a obrigação

\footnotetext{
${ }_{335}$ Art. 27: "El presente capitulo establece las normas que regirán los hechos o actos jurídicos, lícitos o ilícitos que, por acción u omisión, causen daño ambiental de incidencia colectiva. Se define el daño ambiental como toda alteración relevante que modifique negativamente el ambiente, sus recursos, el equilibrio de los ecosistemas, o los bienes o valores colectivos."

336 Art. 28: "El que cause el daño ambiental será objetivamente responsable de su restablecimiento al estado anterior a su producción. En caso de que no sea técnicamente factible, la indemnización sustitutiva que determine la justicia ordinaria interviniente, deberá depositarse en el Fondo de Compensación Ambiental que se crea por la presente, el cual será administrado por la autoridad de aplicación, sin perjuicio de otras acciones judiciales que pudieran corresponder."

${ }^{337}$ Neste sentido, leciona Alicia Morales Lamberti (2008, p. 96): "El establecimiento con carácter obligatorio de asegurar los daños ambientales, cuando no existe un mercado de seguros ambientales, genera um primer obstáculo para su operatividad: el seguro ambiental es un instrumento financiero de gestión ambiental que responde a la lógica de um mercado de libre competencia que como tal, no
} 
imposta aos poluidores em contratar tais ferramentas, visto que ainda pendente, nos dias atuais, a devida regulamentação jurídica, bem como ausente a oferta em grande escala no mercado empresarial dos produtos, o que inviabilizaria a apropriada implementação.

\subsection{As RESOLUÇÕES NORMATIVAS TENDENTES A EFETIVAR A OBRIGATORIEDA- DE DO SEGURO AMBIENTAL ARGENTINO}

Considerando que apesar de haver lei prevendo o seguro ambiental obrigatório no ordenamento jurídico argentino, não há lei no país que regule a matéria de maneira pormenorizada, culminando, pois, em uma lacuna legislativa. Verificada tal omissão, o Estado se viu obrigado a editar resoluções normativas, através, sobretudo, da Secretaria de Meio Ambiente e Desenvolvimento Sustentável, com o objetivo de dar um formato jurídico ao instituto em questão. As resoluções visam, sobremaneira, estabelecer condições necessárias para a oferta de garantias financeiras específicas para cobrir os danos ambientais coletivos, além de padrões técnicos que permitam unificar critérios no momento da exigência da reparação do dano.

\subsubsection{Atividades que necessitam da contratação de seguro ambiental}

De acordo com informações de Guadalupe Torres (2008), a primeira resolução expedida para regulamentar o seguro ambiental foi a de número 177/07, ditada pela Secretaria de Meio Ambiente e Desenvolvimento Sustentável. Esta resolução estabeleceu, através de anexos, quais as atividades perigosas que devem ser acobertadas pelo seguro ambiental. Para tanto, valeu-se de uma fórmula em que se consideram os seguintes elementos: o risco da atividade, a dimensão do empreendimento e, por fim, a localização do agente poluidor. $\mathrm{O}$ resultado desta fórmula determina o nível de complexidade ambiental, sendo este graduado em 3 (três) categorias. Exclui-se de tal gradação as atividades de transporte de substâncias e resíduos perigosos, de forma que esta categoria, devido ao seu alto grau de risco, é obrigada a contratar o seguro ambiental, independente de critérios ou classificações. A referida fórmula considera, ainda, critérios conforme dispõe as normas do Código Industrial Internacional Unificado (C.I.I.U.).

Essa mesma resolução criou a Unidade de Avaliação de Riscos Ambientais, cujos objetivos são os de analisar as garantias financeiras oferecidas pela seguradora com um enfoque preventivo, oferecer pautas técnicas para a

puede ser creado por ley." 
reparação do dano ambiental e auditar o cumprimento dos planos previstos. Ocorrendo o sinistro, o órgão elabora guias para a reparação do dano. Por fim, a resolução de número 177/07 admite o auto-seguro, que, por ser de mais fácil aplicação do que se contratar um seguro, seria uma opção interessante para aquelas empresas obrigadas a contratar seguro ambiental, desde que comprovem solvência econômica e financeira. Esse instituto já era previsto nas leis de número 25.612 e 25.670 , como citado anteriormente, sendo uma alternativa válida ao seguro ambiental. A não previsão do auto-seguro na Lei de número 25.675 é criticada por alguns doutrinadores argentinos ${ }^{338}$, que sustentam que ao prever tão somente o seguro ambiental como forma de instrumento de proteção ao meio ambiente, a norma acaba por prejudicar algumas empresas que poderiam dele se valer, sobretudo as pequenas e médias empresas.

\subsubsection{Os sujeitos do contrato de seguro e a definição do dano a ser reparado}

As resoluções conjuntas de número 98/2007 e 1973/2007, que tiveram a participação de setores envolvidos no assunto, tais como os possíveis segurados e o setor industrial, vieram para estabelecer pautas básicas a serem seguidas no momento em que a empresa contratar o seguro ambiental, além de condições contratuais a serem respeitadas pelos contratantes, sobretudo com relação à apólice de seguro.

Referidas resoluções, além de estabelecerem os sujeitos do contrato de seguro (segurado, segurador e tomador), regulamentam o objeto e o alcance do contrato, ao dizer que o seguro deve ter fundos para cobrir a recomposição do dano ambiental de caráter coletivo causado de forma acidental, não importando se tiver sido causado de maneira súbita ou gradual; o que se revela um dos méritos dos diplomas normativos. Neste momento, cabe fazer uma breve observação sobre aquele que contrata o seguro ambiental. De acordo com o ordenamento argentino, todo aquele que realizar atividades perigosas ao meio ambiente deve contratar o seguro ambiental, independente do porte e das condições financeiras da empresa. Na Espanha, a título de exemplo, não é assim. Neste país, cuja legislação sobre o assunto é mais recente, do ano de 2007, as empresas que realizam atividades com preço de reparação de eventual dano ambiental avaliado em até trezentos mil euros estão isentas de contratar o seguro ambiental. Para as empresas em que tal montante é avaliado entre trezentos mil e dois milhões de euros, existe igual isenção, desde que demonstrada a implementação de

\footnotetext{
${ }^{338}$ Por todos, citamos Guadalupe Torres (2008): "Cabe destacar que esta fue una de las tantas críticas que recibió la redacción del Art. 22 de la LGA ya que había seguido un criterio restringido-limitado, acotando sin necesidad ciertas garantías que en muchos casos podrían ser de utilidad, sobre todo para las pequeñas y medianas empresas".
} 
sistemas de gestão e de auditoria ambientais sobre suas atividades.

Retomando ao disposto nas resoluções normativas conjuntas de número 98/2007 e 1973/2007, considerar-se-á causado o dano ambiental coletivo quando houver elevado risco de moléstia à saúde humana ou, então, quando se verificar a destruição de um recurso natural de maneira que fique impossibilitada sua auto-regeneração.

\subsection{A eSFera de Cobertura do Seguro AMbiental}

Impõe-se dizer que o seguro ambiental oferece cobertura apenas para aqueles danos que se manifestaram após a sua contratação. Dessa forma, é recomendável que o segurador realize um estudo prévio na área onde se situa o segurado a fim de detectar danos preexistentes, que são de inteira responsabilidade do último. Logo, temos que as resoluções conjuntas de número 98/2007 e 1973/2007 delimitaram o alcance de "recomposição" prevista no artigo 22 da Lei de número 25.675, ao estabelecerem que o dano pode ter sido causado de maneira súbita ou gradual, e que tal dano só será acobertado pelo segurador se for posterior à contratação do seguro ambiental. Cabe dizer, ainda, que se estipulou um prazo mínimo de 2 (dois) anos, a contar do término do contrato de seguro, para que algum prejudicado pelo dano ambiental possa acionar a seguradora em casos de eventuais danos ocorridos na vigência do contrato.

Apesar de a Lei de número 25.675, prever que o seguro deve cobrir os danos causados de maneira súbita ou gradual, isso dificilmente ocorre na prática; sobretudo, pela grande dificuldade de se comprovar o nexo causal entre a conduta do agente poluidor e o dano causado. Para exemplificar, de acordo com dados do Colégio de Mediadores de Seguros de Alicante, na Espanha, citados por Raquel Antón Cantos (apud LAMBERTI, 2008) apenas 1\% das empresas potencialmente poluidoras do país contam com um seguro que tenha cobertura para danos graduais. Além disso, essas poucas empresas, normalmente do setor químico, siderúrgico ou gestoras de resíduos, contratam este tipo de cobertura por exigência da Administração Pública, que demanda a garantia para a concessão de licenças ambientais que necessitam para o seu funcionamento.

Sendo assim, de acordo com Alicia Morales Lamberti (2008), professora de Direito Ambiental da Universidade Nacional de Córdoba, observamos três condições para que a seguradora cubra os prejuízos decorrentes do dano ambiental em sua modalidade súbita, que é a mais contratada pelas empresas,

a) La primera manifestación constatable de la contaminación ha de registrarse dentro del período del seguro. Se entiende por primera 
manifestación constatable el momento en que se perciben por primera vez signos externos o indiciários sobre la posible existencia de la perturbación del medio ambiente; b) El acontecimiento causante de la contaminación ha de ser identificado; especificamente, sin que pueda atribuirse a un hecho originado con anterioridad a La fecha de efecto del seguro y c) La reclamación de los perjudicados por el resarcimiento de los daños irrogados ha de formularse durante el periodo de vigencia de la póliza o bien dentro del plazo de dos años a contar desde La extinción del contrato de seguro.

Nos casos em que a seguradora não é obrigada a reparar o dano, posto que anterior à sua contratação, alguns doutrinadores entendem que o Estado deve arcar com a recomposição do dano causado, se insolvente a empresa causadora do dano. A proposta resulta na socialização dos prejuízos entre todos os contribuintes, o que é passível de críticas, visto que prejudicaria toda a coletividade, que teria que arcar com dano que não causou.

\subsection{O VALOR DA APÓLICE}

Um aspecto controvertido destas resoluções conjuntas (as de número 98/2007 e 1973/2007) diz respeito ao montante que a apólice de seguro deve cobrir. De acordo com as resoluções, a seguradora está obrigada a pagar indenização somente sobre o valor que foi pactuado quando da formação do contrato. A Lei de número 25.675, por sua vez, diz que o seguro contratado deve ser capaz de garantir o pagamento de todo o dano causado ao meio ambiente, de maneira integral. Essa divergência gera insegurança tanto para o segurado como para o segurador, pelo que, o ideal, segundo Guadalupe Torres, seria que o Congresso Nacional daquele país editasse uma lei para colocar fim à controvérsia.

Ainda no tocante à existência ou não de um limite do valor da apólice de seguro, a Suprema Corte de Justiça da Argentina já se manifestou sobre o assunto, embora não tenha abordado especificamente o seguro ambiental. A Suprema Corte entende que a matéria deve ser vista de maneira restritiva, de modo a prevalecer a liberdade das partes quando da formação do contrato, neste caso, no valor da apólice ${ }^{339}$. Justifica a decisão, sobretudo, citando o princípio da prevenção. Argumenta que se o segurado transfere totalmente o risco de sua atividade à seguradora, não haveria estímulos para que ele atue de forma preventiva - a evitar acidentes ambientais - apesar de atingir o objetivo de

${ }^{339}$ C. 724. XLI; RHE. Cuello, Patricia Dorotea c/Lucena, Pedro Antonio. 07.08.2007. t. 330, p. 348. 
reparação do dano. A prevenção seria alcançada, por outro lado, se uma parte da indenização tivesse que ser paga pelo segurado, atingindo diretamente seu patrimônio; o que poderia inibi-lo de poluir, acarretando um maior cuidado por parte deste na prevenção do dano. Contudo, tal posicionamento pode surtir um efeito desestimulante ao segurado, na medida em que este não visualizará tantas vantagens em contratar um seguro ambiental se, ocorrendo o sinistro, tiver que, além de pagar mensalmente o prêmio à seguradora, pagar indenizações aos lesados pelo dano.

Nesse tocante, Alicia Morales (2008) propõe que se estabeleça normativamente um limite para a apólice de seguro. Isto porque uma das funções do seguro ambiental diz respeito ao seu caráter reparatório, de modo que o dano seja reparado diretamente pela seguradora, sem que a empresa poluidora possa alegar insolvência e descumprir sua obrigação. A autora ressalta, contudo, que esse limite seria exclusivamente para o seguro, e não para o valor total do dano causado. Uma vez que o valor total do dano supere a soma assegurada, caberia à empresa poluidora pagar a diferença.

\subsection{O atual estágio do seguro ambiental na Argentina}

A jurisprudência argentina vem decidindo, ainda timidamente, em favor da implementação do seguro ambiental obrigatório. Em decisão proferida em 2005, a Corte Suprema Argentina solicitou a algumas empresas litigantes que informassem se haviam contratado seguro ambiental nos termos da Lei de número $25.675^{340}$. Em uma posição mais arrojada, na mesma ocasião, alguns ministros daquela corte, minoritariamente, consideraram que as empresas deveriam ser compelidas a contratar o seguro ambiental; estabeleceram, inclusive, prazo máximo de 10 (dez) dias para tanto. Na oportunidade, as empresas responderam que não haviam contratado o seguro em função de não haver apólices de tal especificidade disponíveis no mercado.

Apesar de a obrigação do seguro ambiental argentino ser plena, sua operatividade e eficácia estão condicionadas a uma realidade fática, que é a oferta pelo mercado segurador de apólices que possam oferecer coberturas aos danos ambientais.

Como bem observa Walter Polido (2007), uma alternativa para o mercado securitário argentino - bem como para qualquer país que esteja iniciando a implementação desta modalidade de seguro, como é o caso do Brasil - seria a formação de um pool de seguradoras e resseguradores, conforme já existente, sobretudo, nos países europeus. Com isso, o risco inerente a este tipo de contrato seria dividido entre as seguradoras.

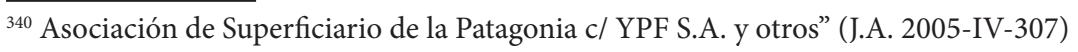


Ainda de acordo com Polido, as vantagens da formação deste pool são consideráveis. É possível citar as seguintes:

- maior capacidade de oferta de cobertura para os riscos inerentes;

- facilidade de subscrição de riscos e coberturas mais complexas poluição gradual, por exemplo;

- representatividade política perante os Órgãos Estatais do Meio Ambiente e outros;

- maior possibilidade de compra de resseguro pelo pool;

- uniformização de estatísticas, disposições tarifárias, clausulados de coberturas;

-minimização dos custos operacionais e administrativos na subscrição de riscos, incluindo aqueles relativos às inspeções técnicas necessárias para a análise de aceitação dos riscos.

Para alguns autores argentinos, ${ }^{341}$ o seguro ambiental obrigatório, apesar de ser uma iniciativa louvável do poder legislativo na defesa do meio ambiente, nos moldes em que foi formulado carece de um maior desenvolvimento, sobretudo técnico, para que possa ser exigido das empresas poluidoras. Argumentase, principalmente, que a matéria ainda necessita de uma regulamentação mais efetiva, sobretudo do Congresso Nacional argentino, e não através de resoluções normativas emitidas pelo Executivo. Isso porque a concretização do instituto exige a elaboração de normas complexas e de largo alcance que, quando realizadas na forma de resoluções, incitam o questionamento de sua constitucionalidade, sob o fundamento de que não possuiriam legalidade para abordar o assunto. Neste sentido, alerta Guadalupe Torres (2008),

La disparidad de textos entre las normas de distinto rango, entre la Resolución Conjunta No 98/2007 y 1973/2007 y el Art. 22 de la LGA, deriva en una gran incertidumbre legal que deberá ser allanada, a mi entender, por una ley emanada del congreso de la Nación. De lo contrario, podrán sucederse planteos de inconstitucionalidad.

Outra forte crítica feita ao instituto diz respeito a sua obrigatoriedade em

\footnotetext{
${ }^{341}$ Por todos, citamos Gabriela Vinocur e Pablo Schatz, que prelecionam que "Sin perjuicio de la incorporación de la tutela ambiental al texto de la Constitución Nacional y de la sanción de normas de presupuestos mínimos de protección ambiental, se evidencia que las autoridades competentes no han encarado aún de manera congruente y definitiva el camino hacia la implementación de un marco que torne apto y viable el desarrollo del mercado de seguros ambientales. Tal extremo resulta necesario para poder llevar a la práctica una herramienta que es fundamental para el avance hacia un modelo de desa-rrollo sustentable."
} 
um momento em que poucas empresas seguradoras oferecem o produto àqueles obrigados a contratá-lo. Visando elidir tal problema, propõe-se que seja adotado um sistema de progressividade, de forma a obrigar, primeiramente, as empresas públicas a contratarem seguradoras, depois, as empresas de grande porte, e, por último, as de pequeno e médio porte. Tal progressividade - gradual - teria o objetivo de fomentar o mercado securitário até que todas as empresas tenham condições de arcar com os custos de um seguro ambiental. É nesta direção que se manifesta a Confederação Argentina das Médias Empresas (CAME) (2009),

[...] ya que no ha establecido un régimen gradual de implementación que creemos hubiera sido pertinente fijándose un cronograma gradual de cumplimiento atado a un orden de sujetos con mejores condiciones de dar cumplimiento a este requerimiento en donde se debería colocar a las personas públicas en primer lugar y luego a las personas privadas (fisicas o jurídicas) que revisten carácter de grandes empresas y por último las personas físicas ojurídicas que revisten el carácter de PyMEs.

O posicionamento da CAME revela-se de acordo com o princípio da progressividade previsto na própria Lei Geral do Meio Ambiente, que em seu artigo $4^{\circ}$ prevê: " [...] Los objetivos ambientales deberán ser logrados en forma gradual, a través de metas interinas y finales, proyectadas en un cronograma temporal que facilite la adecuación correspondiente a las actividades relacionadas con esos objetivos. " Mais uma vez, a prevalência de resoluções normativas sobre lei nacional poderia gerar a tese de inconstitucionalidade daquelas.

Através de um breve apanhado das características do seguro ambiental obrigatório argentino, podemos fazer um breve resumo dos elementos que o cercam.

Primeiramente, podemos dizer que as atividades a serem acobertadas pelo seguro ambiental são definidas por normas técnicas, através da consideração de alguns critérios, tais como o risco da atividade, a dimensão do empreendimento e a localização do poluidor.

Com relação aos sujeitos do contrato de seguro, temos, principalmente, o segurado e o segurador. O primeiro será o agente poluidor, pessoa física ou jurídica, que estará obrigado a contratar o seguro ambiental junto ao segundo sujeito, uma empresa seguradora que ofereça tal produto no mercado.

Por sua vez, o dano causado ao meio ambiente a ser reparado será aquele de caráter coletivo, quando se verificar elevado risco à saúde humana ou impossibilitar a auto-regeneração de determinado recurso natural.

No que diz respeito ao alcance da cobertura do seguro ambiental, temos que o seguro, do modo como está previsto, abarca os danos súbitos e graduais. Deve-se frisar que o dano acobertado deve ter sua manifestação após a 
contratação do seguro, cabendo a ressalva de que eventual lesado poderá acionar a seguradora no prazo mínimo de 2 (dois) anos após o término do contrato.

Por fim, temos o valor da apólice do seguro ambiental, que é um dos assuntos mais controvertidos deste instituto. Na Argentina, a matéria é regulada tanto por lei nacional, quanto por resoluções normativas do Governo. Por serem de competências distintas é que geram calorosas discussões, além de teses de inconstitucionalidade. De acordo com a lei, o valor da apólice deve ser capaz de cobrir integralmente o dano causado ao meio ambiente. As resoluções, por sua vez, dizem que há um limite para esse valor, que seria pactuado entre a seguradora e o segurado quando da celebração do contrato.

Como visto, a iniciativa de instituição do seguro ambiental obrigatório na Argentina é admirável, e, como todo assunto novo e complexo, gera dúvidas e temores. A partir da análise da implementação do instituto naquele país, bem como os equívocos que se seguiram à sua instituição, podemos melhor apreciar os projetos de lei em trâmite no Congresso Nacional brasileiro, ressaltando seus pontos positivos e alertando sobre seus pontos negativos. É o que será feito no capítulo seguinte.

\section{Considerações Sobre os Projetos de Lei EM TRÂMite no Congresso NACIONAL QUE BUSCAM IMPLEMENTAR O SEGURO AMBIENTAL NO BRASIL}

No presente capítulo, temos o objetivo de expor os projetos de lei atualmente em trâmite no Congresso Nacional que desejam instituir o seguro ambiental em nosso país, buscando elucidar seus principais pontos controversos. Além disso, será dito em que fase esses projetos estão em nossas casas legislativas, bem como os apoios e críticas que receberam pelas comissões por onde passaram até o momento.

\subsection{O PROJETO DE LEI N ${ }^{0}$ 937/2003}

O primeiro projeto de lei a ser analisado, de autoria do Deputado Federal Wanderley Alves de Oliveira, propõe alterações na Lei nº 6.938/1981 (Lei da Política Nacional do Meio Ambiente). Pretende inserir no artigo 10 desta lei o $\S 5^{\circ}$, que teria o seguinte teor:

“Artigo $10[\ldots]$

$\S 5^{\circ}$ Sem prejuízo de outras exigências estabelecidas no âmbito do processo de licenciamento ambiental, o órgão licenciador pode estabelecer como condição para a concessão da licença ambiental: 
I - a contratação, pelo empreendedor, de seguro de responsabilidade civil por dano ambiental;

II - a realização periódica, pelo empreendedor, de auditoria ambiental;

III - a manutenção de técnicos especializados em meio ambiente, nos quadros funcionais da pessoa jurídica responsável pelo empreendimento licenciado, para acompanhar o funcionamento deste, ou a contratação de terceiros, em caráter permanente, com a mesma finalidade".

Adentrando especificamente no seguro ambiental proposto pelo projeto ora analisado, seu autor argumenta que esse tipo de seguro seria uma das únicas formas de se certificar que o dano ambiental causado será efetivamente reparado pelo causador, e não suportado por toda a coletividade, sobretudo sob a forma de impostos, que é o que infelizmente ocorre em nosso país. Neste tocante, transcrevemos parte da justificativa apresentada pelo autor do projeto:

O seguro de responsabilidade civil por dano ambiental é praticamente a única forma de assegurar que danos de maior gravidade eventualmente causados sejam, de fato, reparados. O capital das empresas responsáveis, na maior parte dos casos, é insuficiente para arcar com as despesas de recomposição do meio ambiente ao status quo ante. O seguro com essa finalidade é bastante difundido em países mais desenvolvidos e, infelizmente, quase não existe em nosso País. Aqui, quando os acidentes ocorrem, parte considerável dos custos da recomposição ambiental acabam recaindo sobre toda a sociedade.

Ressalte-se que, no modo como o seguro está exposto, ele não pode ser considerado obrigatório. Isso porque ficaria a cargo dos órgãos licenciadores emitirem parecer sobre a necessidade ou não de determinada empresa contratálo para que lhe seja emitida licença ambiental. Essa medida discricionária é um dos principais pontos de diferença entre este projeto e os demais que serão estudados mais adiante. No momento, resta-nos analisar como se deu o debate sobre este projeto de lei nas comissões legislativas pelas quais passou.

\subsubsection{Posicionamentos favoráveis ao projeto}

A primeira comissão a se manifestar sobre o projeto de lei n ${ }^{\circ}$ 937/2003 foi a Comissão de Defesa do Consumidor, Meio Ambiente e Minorias. Esta comissão, através do relator do projeto ora analisado, Deputado Sarney Filho, 
cita o artigo 225, $\S 3^{\circ}$ da Constituição Federal e o artigo $14, \S 1^{\circ}$, da Lei $n^{\circ} 6.938 / 1981$ para explicitar que a responsabilidade daquele que causar dano ambiental é objetiva. A partir de tal constatação, conclui que o seguro ambiental seria uma ferramenta de grande valia para aperfeiçoar as normas de proteção ambiental.

Contudo, o deputado alerta para o fato de que as previsões legais ambientais, apesar de serem modernas e contundentes, carecem de instrumentos que as viabilizem, sob pena de se tornarem ineficazes, verdadeiras letras mortas em nosso ordenamento jurídico.

Alerta, ainda, para o fato de que quando ocorrem desastres ambientais de grandes proporções, os responsáveis muitas vezes não dispõem de recursos financeiros para cobrir os gastos com a reparação do dano. De acordo com o parlamentar, o seguro ambiental seria uma ótima alternativa para casos como esse, já que quem seria acionado seria a seguradora, e não a empresa poluidora.

Outro mérito da proposta diz respeito ao caráter auxiliar que o seguro teria no controle ambiental que o Sistema Nacional do Meio Ambiente (SISNAMA) exerce. Isso porque os prêmios calculados pelas seguradoras seriam maiores ou menores de acordo com o comportamento dos poluidores em potencial, pelo que haveria um incentivo para comportamentos mais cuidadosos por parte dos segurados. Ressaltese, ainda, que toda seguradora tem o direito-dever de fiscalizar o objeto de seu contrato, o que aqui não seria diferente. Fomentar-se-ia um comportamento mais protetivo ao meio ambiente, bom para a empresa - que pagaria um prêmio de valor reduzido - e para o meio ambiente - que seria menos lesado.

Encerrada a apreciação do projeto pela Comissão de Defesa do Consumidor, Meio Ambiente e Minorias, este foi encaminhado para a Comissão de Constituição e Justiça e de Cidadania. Dita comissão, em um primeiro momento, manifestou-se, através do voto do Deputado Marcelo Ortiz, pela aprovação do projeto. Observou que estavam obedecidos todos os ditames constitucionais formais que regulam o trâmite legislativo da matéria (artigo 24, VI, artigo 48 e artigo 61, caput, todos da Constituição Federal).

O último pronunciamento daquela comissão, até o presente momento, foi a apresentação do voto em separado do Deputado Moreira Mendes, que discordou do parecer favorável ao projeto de lei ora comentado e que prevaleceu a este. No próximo tópico passaremos a analisar os motivos dessa discordância, bem como suas conseqüências.

\subsubsection{Posicionamentos contrários ao projeto}

O voto destoante fundamenta-se, basicamente, em uma suposta intervenção indevida do Estado na economia. Alega a inconstitucionalidade do projeto 
por afronta aos artigos 170 e 174 da Constituição Federal, na medida em que atentariam contra a liberdade da empresa em gerir seus bens e meios de produção.

Segundo este voto vencedor, o presente projeto de lei extrapola os limites constitucionais de normatização e de exercício de poder de polícia do Estado. Isso com fulcro no artigo 170 da Constituição Federal, que enumera princípios basilares da atividade econômica, abarcando o princípio da liberdade de iniciativa e da defesa do meio ambiente.

Destaca-se, ainda, um ponto importante do projeto de lei, que seria a discricionariedade atribuída aos órgãos ambientais para concederem ou não a licença ambiental, não havendo no projeto critérios objetivos para tais decisões. Atenta para o risco de lesão à competitividade entre as empresas e à livre concorrência (artigo 170, IV, Constituição Federal), posto que poderiam ser aplicadas as imposições previstas sobre algumas empresas em benefícios de outras, que apesar de estarem em situações semelhantes não teriam que arcar com os custos de implantação das exigências previstas pela lei.

Por fim, o Deputado vale-se do argumento de que o mercado securitário brasileiro não está preparado para a demanda que o projeto invariavelmente traria. Argumenta que seria irracional imaginar a paralisação do processo de licenciamento ambiental quando a empresa não contratar o seguro ambiental que lhe for imposto, justamente porque não haveria oferta de tal produto.

Após esse parecer desfavorável ao projeto de lei em comento, o entendimento majoritário, que antes caminhava no sentido da aprovação, modificou-se de modo que a posição do primeiro relator da CCJ passou a constituir-se minoritária. A partir disso, o projeto de lei $n^{\circ}$ 937/2003 foi arquivado em janeiro de 2011. Entretanto, após requerimento interposto pelo autor do projeto, este foi desarquivado em maio de 2011. Desde então não houve qualquer manifestação sobre a proposta.

\subsection{O PROJETO DE LEI N ${ }^{0} 2313 / 2003$}

Passamos agora à análise do projeto de lei no 2313/2003, que teve origem a partir de sugestão apresentada pela Associação Total dos Indivíduos da Terra Unidos em Defesa da Ecologia (ATITUDE), acatada pela Comissão de Legislação Participativa da Câmara dos Deputados.

Este projeto propõe mudanças legislativas mais amplas e ambiciosas do que o projeto anteriormente estudado. Modifica o Decreto Lei $n^{0} 73 / 66$, que dispõe sobre o Sistema Nacional de Seguros Privados e regula as operações de seguros e resseguros. Pretende acrescentar a alínea "n" ao artigo 20 do Decreto, que passaria a ter o seguinte teor: 
"Art. 20. Sem prejuízo do disposto em leis especiais, são obrigatórios os seguros de:

$[\ldots]$

n) responsabilidade civil do poluidor, pessoa física ou jurídica que exerça atividades econômicas potencialmente causadoras de degradação ambiental, por danos a pessoas e ao meio ambiente em zonas urbanas ou rurais".

Como se observa, o projeto em comento tem a pretensão de, além de prever expressamente o seguro ambiental, tornar obrigatória a sua contratação pelas pessoas, físicas ou jurídicas, que sejam potencialmente causadoras de dano ambiental.

Passaremos a expor, a seguir, três tópicos que foram debatidos com maior afinco nas comissões por onde o projeto passou até o momento. Primeiramente, propõe-se que o valor do prêmio do seguro seja calculado pelo Instituto de Resseguros do Brasil (IRB). As indenizações por danos ambientais, por sua vez, seriam pagas às secretarias de meio ambiente dos Municípios, que, além disso, teriam a atribuição de aplicarem multa àqueles que, uma vez obrigados, deixarem de contratar o seguro ambiental. Por fim, o valor do prêmio pago pelos poluidores não seria destinado integralmente às seguradoras. Estas ficariam com 58\% da arrecadação, enquanto que a União, Estados e Municípios ficariam com 30\%, distribuídos proporcionalmente às suas arrecadações, sendo que os $12 \%$ restantes seriam destinados ao Fundo Nacional do Meio Ambiente.

Veremos, a seguir, como se manifestaram as comissões por onde o projeto de lei passou. Até o momento, manifestaram-se a Comissão de Meio Ambiente e Desenvolvimento Sustentável e a Comissão de Finanças e Tributação. Aguarda-se, ainda, manifestação da Comissão de Constituição e Justiça, o que não ocorreu até o encerramento do presente estudo.

\subsubsection{Posicionamentos favoráveis ao projeto}

Aprimeira comissão a se manifestar sobre o projeto em comento foi a de Meio Ambiente e Desenvolvimento Sustentável. O deputado da comissão encarregado de relatar o projeto de lei concordou com a idéia proposta, por vislumbrar um instrumento extremamente útil ao meio ambiente, mais especificamente em favor da implementação da Política Nacional do Meio Ambiente.

Em que pese os méritos da proposta, o relator destacou que alguns pontos do projeto mereceriam ajustes, pelo que propôs algumas emendas modificativas. 
Inicialmente, destaca-se a obrigatoriedade que o projeto impõe a todas as pessoas que possam ser consideradas potencialmente poluidoras em contratarem o seguro ambiental. Isso porque a própria legislação ambiental prevê, através do artigo $3^{\circ}$, IV, da Lei $n^{\circ} 6.938 / 1981$, um amplo conceito de que poluidor seria a "[...] pessoa física ou jurídica, de direito público ou privado, responsável, direta ou indiretamente, por atividade causadora de degradação ambiental".

Para contornar essa situação de uma aparente impossibilidade de se instituir o seguro ambiental como obrigatório, o relator propõe que dita obrigatoriedade deve ser observada em casos específicos, nos quais o órgão do SISNAMA a coloque como requisito para a concessão de licença ambiental. Neste sentido, são propostas duas emendas. Uma delas ${ }^{342}$ visa alterar o principal dispositivo criado pelo projeto de lei, que altera a lei do Sistema Nacional de Seguros Privados, e a outra ${ }^{343}$ tem por objetivo adicionar o parágrafo $5^{\mathbf{0}}$ ao artigo 10 da Lei da Política Nacional do Meio Ambiente, em termos semelhantes ao projeto de lei anteriormente estudado. Ambas as propostas atuariam no sentido de amenizar a exigência pensada pelo projeto inicial, posto que muito ampla, o que inviabilizaria a sua aplicação.

Mesmo com todas as modificações propostas pela Comissão de Meio Ambiente e Desenvolvimento Sustentável, o relator opinou pela aprovação do projeto, considerando que o seguro ambiental seria uma ferramenta extremamente importante ao meio ambiente. Ressaltou que o instituto deveria ser integrado ao nosso ordenamento jurídico de maneira obrigatória. Não foi esse, contudo, o entendimento da Comissão de Finanças e Tributação, como se verá a seguir.

\subsubsection{Posicionamentos contrários ao projeto}

Após manifestação da Comissão de Meio Ambiente e Desenvolvimento Sustentável, o projeto de lei n ${ }^{\circ}$ 2313/2003 passou à apreciação da Comissão de Finanças e Tributação. Esta comissão, especificamente no tocante ao assunto de sua competência, qual seja, o de analisar a repercussão de determinado projeto para os cofres públicos, entendeu ser o projeto benéfico, tendo em vista a criação de fonte de receita para o Estado, sobretudo para o Fundo Nacional

\footnotetext{
${ }^{342}$ Emenda ${ }^{\circ}$ 1: "Art. 20. [...]: n) responsabilidade civil do poluidor, pessoa física ou jurídica que exerça atividades econômicas potencialmente causadoras de degradação ambiental, por danos a pessoas e ao meio ambiente em zonas urbanas ou rurais, nos casos em que o seguro seja exigido pelo órgão licenciador do Sistema Nacional do Meio Ambiente (SISNAMA), como requisito para a concessão da licença ambienta." (grifo nosso).

${ }^{343}$ Emenda no 8: "Art. 10 [...]: $\$ 5^{\circ} \mathrm{O}$ órgão licenciador pode impor a contratação de seguro de responsabilidade civil por dano ambiental como exigência prévia para a concessão da licença de que trata este artigo".
} 
do Meio Ambiente. Referida receita seria oriunda, sobretudo, das multas a serem aplicadas àqueles que descumprirem a imposição de contratar o seguro ambiental, que passaria a ser obrigatório em diversas situações.

Apesar de reconhecer os benefícios financeiros e tributários que o projeto traria aos cofres públicos, esta comissão, finalizando seu raciocínio, adentrando nas questões ambientais e securitárias do projeto de lei, manifestou-se pela sua rejeição, apesar das emendas modificativas apresentadas pela Comissão de Meio Ambiente e Desenvolvimento Sustentável. Veremos, a seguir, os motivos que levaram a tal posicionamento.

O relator do referido projeto rechaça a proposição de que o valor do prêmio seja calculado pelo Instituto de Resseguros do Brasil. Considera absurda tal proposta, uma vez ausente a competência da empresa mista para tanto, já que seria competente apenas para regular as atividades de resseguro, co-seguro e retrocessão. Ao praticar qualquer atividade além dessas, estaria agindo fora de seus limites, de maneira ilegal. Ademais, o valor do prêmio, como regra geral, é calculado pela própria seguradora, como bem explica o relator da Comissão de Finanças e Tributação em seu voto:

[...] o seguro opera em bases técnico-atuariais bastante complexas. Uma das condições da operação de seguros é o conhecimento profundo do risco a ser assumido pela seguradora. Sem esse conhecimento o valor do prêmio tende a ser o próprio risco da carteira. Como o projeto de lei determina que o estabelecimento do valor do prêmio seria competência do IRB, criarse-ia um impasse intransponível. Nenhuma seguradora pode ser obrigada a aceitar um determinado risco que ela desconheça as particularidades ou que entenda não dispor de condições técnicas adequadas para prestar garantia. Uma das práticas universais do setor de seguro é que o cálculo do prêmio é feito pela seguradora que opera o risco.

A previsão que o IRB faça o cálculo do prêmio altera drasticamente um dos pilares da atividade de seguros.

Continuando, revela que, nos moldes em que está previsto, desconsiderando os elementos básicos de cada tipo de empresa, isto é, seu tamanho, seu ramo de atuação, sua localização, entre outros fatores, o seguro ambiental obrigatório seria a criação desnecessária de mais um ônus sobre o setor produtivo. Ônus este que seria fatalmente repassado aos consumidores, através do inevitável aumento do preço dos produtos.

Somado a isso, temos que, em virtude de o valor do prêmio ser destinado parcialmente ao Poder Público, estaríamos diante de um tipo de tributação 
indireta, através de arrecadação de receitas para o Poder Público, o que certamente não deveria ser a razão de existir do instituto ora abordado.

Como visto, o valor do prêmio deve ser estabelecido pela seguradora, que parte de uma análise das características básicas de cada situação empresarial. Para tanto, vale-se de cálculos de probabilidade de ocorrência do sinistro, sendo que tal procedimento faz parte do contrato estabelecido entre segurado e seguradora (TRENNEPOHL, 2008).

Por todas as críticas expostas ao presente projeto, vislumbramos que o projeto de lei anteriormente estudado é mais coerente e de mais fácil aceitação pelo mercado securitário brasileiro, além de estar em melhor consonância com nosso ordenamento jurídico, consideradas as normas de direito econômico e de direito ambiental.

\subsection{A proposta de EMENda À Constituição No 82/2007}

Aúltima proposta legislativa a ser estudada é a $\mathrm{PEC} \mathrm{n}^{\circ} 82 / 2007$, de autoria da Senadora Maria do Carmo Alves. Este projeto tem por objetivo instituir em nosso ordenamento jurídico o seguro ambiental, em sua modalidade obrigatória. Como se vislumbra pela própria natureza da proposta, essa implementação ocorreria em nossa Constituição Federal, que passaria a ter adicionado ao seu artigo 225 o parágrafo $7^{\circ}$, nos seguintes moldes:

Art. 225. [...]

$\S 7^{\circ}$ A lei disporá sobre a obrigatoriedade de seguro de responsabilidade civil nas hipóteses de atividades lesivas ou potencialmente danosas ao meio ambiente.

A idealizadora da proposta, em sua justificação, argumenta que existem muitas atividades que poderiam causar riscos ao meio ambiente e que, em grande parte dos casos, a obrigação de reparar o dano ou não é cumprida ou o é demasiadamente tarde, em virtude da lentidão dos processos judiciais. Nesse sentido, sustenta que a imposição para que o empreendedor contrate um seguro ambiental se mostra razoável.

A Senadora continua sua justificativa dizendo que o seguro ambiental teria, como já dito no primeiro capítulo deste trabalho, a função dúplice de prevenção e de reparação. Em suas palavras:

[...] pela primeira vez, surge uma modalidade de seguro que transforma as seguradoras em verdadeiras parceiras do Poder Público. Explica-se: 
nenhuma seguradora concede cobertura a danos ambientais sem antes se certificar que o segurado tenha efetivamente adotado as medidas preventivas para evitar a ocorrência de sinistro, o que, no caso, incentivaria o cumprimento rigoroso da legislação ambiental. Até porque o valor do prêmio guarda relação com a qualidade da gestão ambiental adotada pela empresa segurada.

Ora, ao se exigir do segurado a preservação do bem, objetivando minorar o risco do sinistro, com a adoção de medidas preventivas, o que se tem é uma contribuição direta e efetiva para a redução dos danos ambientais. Esse papel de prevenção, da qual as seguradoras não podem abrir mão, é um dos mais efetivos instrumentos contra danos ambientais, ao garantir dúplice proteção - prevenção e cobertura.

Encaminhada a proposta para a Comissão de Constituição, Justiça e Cidadania, a relatora responsável emitiu seu voto no sentido da aprovação do projeto.

A relatora inicia seu voto dizendo que a instituição do seguro ambiental no Brasil já em caráter compulsório deveria ser feita, como o foi, através de emenda constitucional, posto que possivelmente sofreria questionamentos norma infraconstitucional o fosse.

Analisando o caráter material da proposta, entende que acarretará em um impulso para as empresas seguradoras, que teriam um vasto mercado a ser explorado. Continua dizendo que haveria uma parceria benéfica entre iniciativa privada e poder público, na medida em que as empresas eminentemente poluidoras seriam incentivadas pelas seguradoras a cumprirem com mais rigor as normas ambientais, de forma a evitar acidentes dessa natureza.

Por fim, reforçando a justificativa da proposta, ressalta a celeridade que o seguro traria na reparação do dano, visto que não haveria a necessidade de uma longa espera por uma decisão judicial, que corriqueiramente leva anos para acontecer.

Por ser mais recente que os projetos de lei anteriormente estudados, após o voto da relatora desta comissão ainda não houve pronunciamento de qualquer outra comissão legislativa sobre o tema, pelo que passaremos, a seguir, a expor a repercussão que a proposta teve no meio securitário e ambiental.

\subsubsection{Repercussões do projeto}

Em posição contrária às esposadas acima, há os que rejeitam a aprovação de um projeto que pretenda obrigar a contratação de seguro ambiental nos moldes propostos pela PEC n⿳ 82/2007. Nesse sentido, Nakiri (2008) destaca diversos obstáculos que poderiam surgir frente à instituição deste novo ramo securitário. 
Primeiramente, questiona a suposta parceria imaginada pela Senadora Maria do Carmo entre a seguradora e o Poder Público. Pergunta o que ocorreria nos casos em que a empresa vistoriada pela seguradora não quiser contratar o seguro, optando por permanecer à margem da lei. Argumenta que, nestes casos, a seguradora não poderia denunciar a empresa, visto que não possui poder de polícia, e, além disso, a relação entre ambas guarda uma relação de confidencialidade, característica inerente aos contratos de seguro. Sustenta, assim, que é fantasioso pensar em cooperação entre seguradora e Administração Pública, nos termos imaginados.

$\mathrm{O}$ autor rebate, ainda, a assertiva do projeto que afirma ser o seguro ambiental uma forma de garantir uma pronta e rápida reparação dos danos ambientais causados, em virtude da morosidade de nosso sistema judiciário. Sustenta que apesar de a legislação ambiental pátria ser calcada na teoria do risco, através da responsabilização objetiva do agente causador do dano ambiental e requerendo a demonstração apenas do nexo de causalidade e do dano causado, tais elementos não são de fácil demonstração. Isso porque antes de se obter a certeza de quem causou o dano e responsabilizar tal agente, se fazem necessários alguns procedimentos, tais quais perícias especializadas no local do dano, análise da relação entre a conduta do possível agente causador do dano e o resultado verificado, além do estabelecimento de um montante justo para a indenização, entre outros fatores que porventura possam surgir. Como se vê, a reparação de um dano ambiental envolve diversos fatores que, pelas suas naturezas, são complexos e levam tempo para permitir que se alcance alguma conclusão satisfatória. Não se questiona, é claro, que adicionando a esse fator a demora costumeira de um processo judicial em nosso país, levar-se-ia um tempo ainda maior para responsabilizar o causador do dano.

Critica-se, por fim, a destinação à administração pública dos valores da indenização em caso de lesão a bens difusos. De acordo com as palavras da autora do projeto, em sua justificativa: "A existência do seguro permitirá que a administração pública, em casos de danos à natureza, seja ressarcida mais rapidamente do que ocorre nos dias de hoje [...]". De modo que poderiam ser observadas diversas falhas por parte do Estado. Este peca por omissão ao não fiscalizar adequadamente as empresas que exercem atividades de alto risco ao meio ambiente, intentando repassar tal responsabilidade às seguradoras. Em seguida, deseja utilizar a estrutura e o dinheiro das seguradoras para receber, mais rapidamente, a indenização que lhe julga devida.

Como se vê, este e os demais projetos analisados anteriormente, bem como os que porventura venham a ser propostos no futuro, por serem ambiciosos e terem a pretensão de instituir uma nova ferramenta de proteção ao meio ambiente, não escaparão de críticas, sobretudo daqueles que defendem ser 
o seguro ambiental uma modalidade de proteção invasiva à livre iniciativa das empresas. Como visto, muitas críticas são pertinentes e devem ser levadas em consideração pelo nosso legislador, enquanto outras carecem de fundamentação e são demonstrativos de uma visão arcaica e conservadora que deve ser superada.

\section{ConClusão}

Através da exposição dos projetos de lei em trâmite no Congresso Nacional que visam instituir o seguro ambiental no ordenamento jurídico pátrio, passando pelas críticas - construtivas e depreciativas - que cada um destes recebeu, buscou-se analisar qual seria a melhor forma de se inserir esta modalidade securitária em nosso país.

Tanto a proposta de emenda à Constituição ${ }^{0}$ 82/2007, quanto o projeto de lei $n^{\circ} 2313 / 2007$, visam instituir o seguro ambiental de maneira obrigatória. A primeira prevê o seguro ambiental obrigatório de maneira abstrata, deixando a cargo de lei infraconstitucional discipliná-lo. É criticada por transferir a responsabilidade inerente ao poder público de fiscalizar as empresas poluidoras às seguradoras. $\mathrm{O}$ segundo, por sua vez, padece de inúmeros defeitos, citados durante o texto, desde a equivocada competência do Instituto de Resseguros do Brasil em calcular o valor do prêmio até a tributação indireta que estaria sendo criada, uma vez que parte do prêmio seria destinado aos cofres públicos. Este último vício acomete também a PEC ${ }^{\circ} 82$.

Por tudo isso, entendemos que o projeto de lei $n^{\circ} 937 / 2003$ seria o mais coerente e adequado à realidade brasileira. Isso porque fica a cargo do órgão ambiental competente a análise da necessidade ou não de determinada empresa contratar o seguro ambiental. Analisa-se, pois, cada caso de maneira concreta, considerando suas peculiaridades. Tal conduta é salutar, na medida em que evita a imposição desnecessária dessa contratação a muitas empresas, sobretudo as de pequeno e médio porte, que $t^{5}$ eriam mais um encargo sobre suas atividades, muitas vezes sem necessidade, o que beneficiaria apenas às seguradoras, que teriam uma maior arrecadação; essa avaliação, como o projeto propõe, somente pode ser feita no caso concreto, considerando, por exemplo, o ramo de atividade da empresa, sua localização, entre outros fatores que poderiam acarretar em prejuízo ao meio ambiente. Não se olvide, contudo, que a lei que vier a instituir o seguro ambiental deverá, ainda, disciplinar pormenorizadamente as nuances deste tipo de seguro, sob pena de se tornar letra morta, o que se verifica, como visto, Argentina. 


\section{REFERÊNCIAS}

BARROS, Antonio Pinho de; VERMELHO JUNIOR, Alcir. Seguro ambiental: Complexo, mas viável. Revista do IRB, Edição on-line, ano 63, número 292, abril/junho de 2003. Disponível em: http://www.irb-brasilre.com.br/revista/292/ revista_292.htm. Acessado em: 16.10.2011.

BRASIL. CÂMARA DOS DEPUTADOS. Projeto de Lei no 937/2003. Brasília, 2003.

BRASIL. CÂMARA DOS DEPUTADOS. Projeto de Lei n ${ }^{\circ}$ 2313/2003. Brasília, 2003.

BRASIL. SENADO FEDERAL. Proposta de Emenda à Constituição $n^{o}$ 82/2007. Brasília, 2007.

BOJUNGA, Luiz. Seguro Ambiental Obrigatório, 2009. Disponível em: http://www. djrlaw.com.br/upload/noticia/42_segs_bojunga.pdf. Acessado em: 22.10.2011.

CAFFERATTA,Néstor.LosprincipiosyreglasdelDerechoAmbiental.Disponível em: http:/www.pnuma.org/deramb/documentos/VIProgramaRegional/3\%20 BASES $\% 20$ DERECHO $\% 20 \mathrm{AMB} / 7 \% 20 \mathrm{Cafferata} \% 20$ Principios $\% 20 \mathrm{y} \% 20$ reglas\%20del\%20der\%20amb.pdf. Acessado em: 02.09.2011.

CONFEDERACIÓN ARGENTINA DE LA MEDIANA EMPRESA Departamento de médio ambiente. Disponível em: http:/www.redcame.org.ar/ adjuntos/MADPF.pdf. Acessado em: 2.09.2011.

COSTA NETO, Nicolao Dino de Castro e. Proteção jurídica ao meio ambiente (I - Florestas). Belo Horizonte: Del Rey, 2003.

FASCINA, Evandro. O seguro ambiental como forma de reparação do dano. 2006. Disponível em: http://www.univates.br/files/files/univates/graduacao/ direito/SEGURO_AMBIENTAL_COMO_FORMA_DE_REPARACAO_DO_ DANO.pdf. Acessado em: 12.08.2011.

FRÚGOLI, Martín Andrés. Daño ambiental y los principios generales del derecho de precaución y prevención. Revista Derecho y Cambio Social, $\mathrm{n}^{\mathrm{o}}$ 19, ano VI, 2009. Disponível em: http://www.derechoycambiosocial.com/ revista019/dano\%20ambiental.htm. Acessado em: .09.2011. 
HAHN, Aucilene Vasconcelos; NOSSA, Valcemiro; REZENDE, Idália Antunes Cangussú. O seguro ambiental como mecanismo de minimização do passivo ambiental das empresas. Revista Universo Contábil, n. 2., p. 61-81, abril/junho de 2010. Disponível em http://www.furb.br/universocontabil. Acessado em: 15.09.2011.

LAMBERTI, Alicia Morales. Estudios de derecho ambiental, vol. 1, n ${ }^{\circ}$ 1, 2008. Disponível em: http://www.acaderc.org.ar/biblioteca/biblioteca-virtual/ estudiosdederechoambiental. Acessado em: 12.08.2011.

MOREIRA, Egon Bockmann. O Direito Administrativo contemporâneo e a intervenção do Estado na ordem econômica. Revista Eletrônica de Direito Administrativo Econômico, Instituto de Direito Público da Bahia, número 1, fevereiro/março/abril de 2005. Disponível em: http://www.direitodoestado. com.br. Acessado em: 15.10.2011.

MUDANÇAS climáticas afetam diretamente as operações de seguros. Revista do IRB, Edição on-line, ano 69, número 308, 2011. Disponível em: http:// www2.irb-brasilre.com.br/documentos/internet_irb/308_web.pdf. Acessado em: 18.10.2011.

NAKIRI, Osvaldo Haruo. RC obrigatório - danos ambientais. Disponível em: http://cadernosdeseguro.funenseg.org.br/secao.php? $=11 \& \mathrm{~s}=$ colunas $\& \mathrm{~m}=246$. Acessado em: 27.10.2011.

POLIDO, Walter Antonio. Contrato de seguro: a efetividade do seguro ambiental na composição de danos que afetam direitos difusos. Revista de Direito Ambiental, n. 45. São Paulo: Editora Revista dos Tribunais, 2007. 